\title{
Full-Wave Rectifier with Zero Standby Current for Vibrational Energy Harvesting Systems
}

\author{
Eunjung Yoon, Minjae Yang and Chonggun $\mathrm{Yu}^{*}$ \\ Department of Electronics Engineering \\ Incheon National University \\ 119 Academy-ro, Yeonsu-gu, Incheon, Republic of Korea \\ *Corresponding author
}

\begin{abstract}
In this paper, a full-wave rectifier (FWR) with zero standby leakage current for vibrational energy harvesting systems is presented. Conventional active FWRs where active diodes are used to reduce the diode voltage drop and increase the system efficiency are usually powered from the output. Nevertheless, a major drawback is that these FWRs consume current from the output storage capacitor even when the system is not harvesting any energy. To overcome the problem, a technique using a simple vibration detector consisting of a peak detector and a level shifter is proposed. The vibration detector detects whether vibrational energy exists or not in the input terminal and disables the comparators when there is no vibrational energy. The proposed FWR with the vibration detector is designed using a $0.35-\mu \mathrm{m}$ CMOS process. Simulation results have verified the effectiveness of the proposed scheme. The maximum power efficiency of the designed FWR is $99.2 \%$. By using the proposed vibration detector, a decrease in standby leakage current by approximately 3,200 times can be achieved.
\end{abstract}

Keywords-full-wave rectifier; vibrational energy; energy harvesting; vibration detector; active diode

\section{INTRODUCTION}

Harvesting energy from the environment to power small electronic systems has recently attracted considerable research interest. Vibrational energy is one of the major energy sources being explored for energy harvesting [1-3]. This form of energy is usually transduced into electrical energy using piezoelectric (PZT) devices. Because the output of a PZT material is similar to an ac voltage, a rectifier (an ac-dc converter) is required to generate a dc power supply for application loads as shown in fig. 1. The rectifier must have high conversion efficiency in order to transfer the maximum amount of power from the harvester to the load.

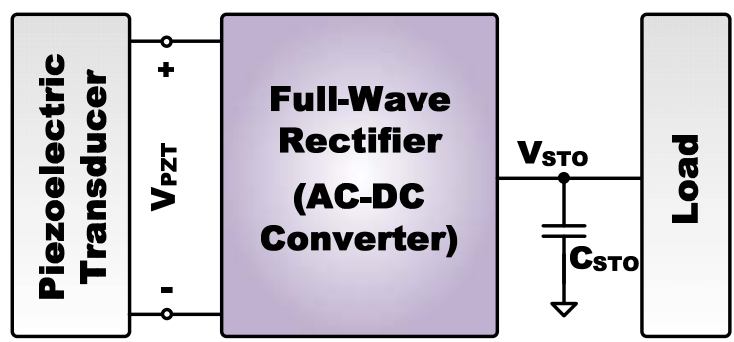

FIGURE I. BLOCK DIAGRAM OF GENERAL VIBRATIONAL ENERGY HARVESTING SYSTEM
Rectifiers based on simple $p-n$ junctions are usually avoided in CMOS processes. Therefore, full-wave rectifiers (FWRs) are usually realized with MOSFETs. Conventional passive FWRs using four diode-connected MOSFETs [3] or gate cross-coupled rectifiers using two MOS diodes and two MOS switches [4] suffer from diode voltage drop that reduces the available output voltage and thus system efficiency. Thus, various active FWRs have been proposed to reduce diode voltage drop and power loss.

The active FWR of fig. 2 is a single-stage configuration [9] This rectifier is consisted of two active diodes and two MOSFET switches. The active diode consists of a PMOS switch and a comparator. The comparator detects the voltage difference between the two terminals $\left(\mathrm{V}_{\mathrm{PZT}}\right.$ and $\left.\mathrm{V}_{\mathrm{STO}}\right)$ and determines when to turn the PMOS switch on or off. The comparators of the active diodes are powered from the output of the rectifier $\left(\mathrm{V}_{\mathrm{STO}}\right)$. The output-powered rectifiers have one major drawback when used for energy harvesting systems. They consume power from the storage capacitor even when the system is not harvesting any energy. If there are long periods of inactivity of the harvester, the storage capacitor will be fully discharged.

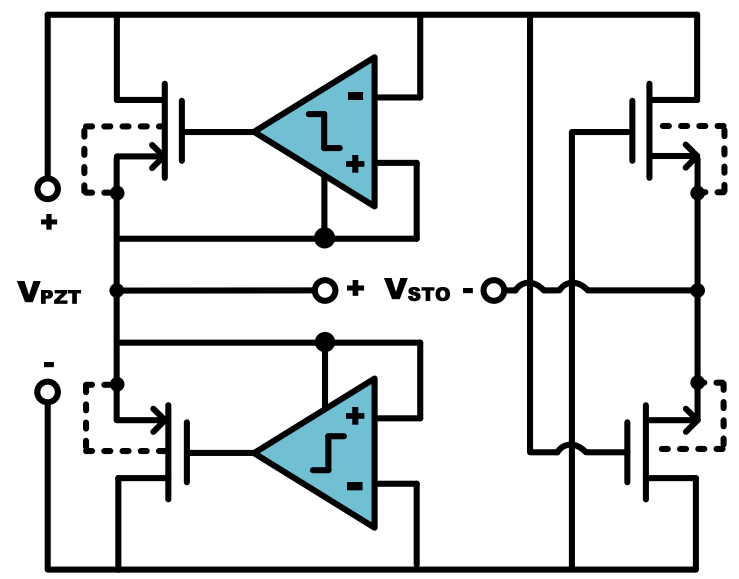

FIGURE II. SINGLE-STAGE full-WAVE RECTIFIER.

To overcome this problem, an input-powered configuration [5] is suggested. The comparator in the input-powered configuration is powered from the input of FWR $\left(\mathrm{V}_{\mathrm{PZT}^{+}}\right)$. The comparator consumes power only when the input is 
sufficiently high. As a result, the rectifier has no standby power consumption when the harvester is not active. However, the comparator is limited in performance because it is powered from the ac voltage. Thus, the peak efficiency of the inputpowered rectifier is limited to $82 \%$ [5], whereas the outputpowered rectifier exhibits a better peak efficiency up to $94 \%$ [7].

In this paper, we propose a technique to prevent the standby leakage current of output-powered active rectifiers by employing a simple vibration detector to turn off the comparator when there is no vibrational energy.

\section{CIRCUIT DESIGN}

The proposed FWR with a vibration detector is shown in fig. 3. The FWR is the single-stage active rectifier as shown in fig. 2 where the comparator is powered from the output terminal, but it is designed to have an enable function. A vibration detector is used to disable the comparator when there is not any alternating signal in the input terminal $\left(\mathrm{V}_{\mathrm{PZT}^{+}}{ }^{+}\right)$. As a result, the rectifier does not consume any standby power when the harvester is not active.

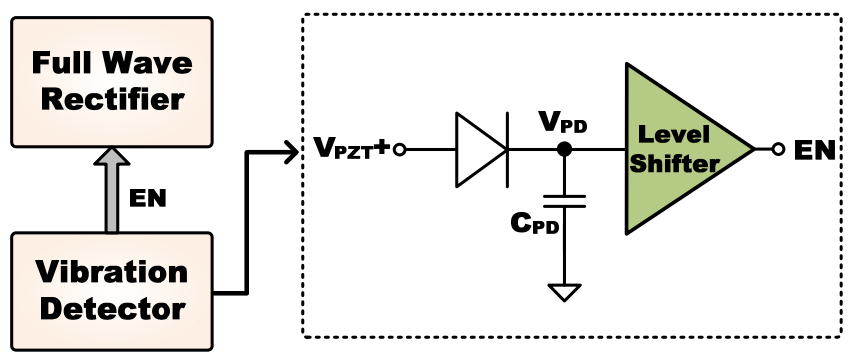

FIGURE III. PROPOSED FWR WITH VIBRATION DETECTOR

The vibration detector comprises a simple peak detector and a level shifter as shown in fig. 3. The designed peak detector consists of a p-type diode of size $800 \mathrm{~nm} \times 800 \mathrm{~nm}$ and a small capacitor $\left(\mathrm{C}_{\mathrm{PD}}=50 \mathrm{fF}\right)$. If the harvester is active, the peak detector detects the peak value of an input ac signal $\left(\mathrm{V}_{\mathrm{PZT}}+\right)$, and thus, the output signal 'EN' goes to a 'high' level that enables the comparator. If there is no vibration or the vibration is weak, the capacitor $\mathrm{C}_{\mathrm{PD}}$ is discharged, and the signal 'EN' returns to a 'low' level, thus disabling the comparator.

As the output of the peak detector $\mathrm{V}_{\mathrm{PD}}$ is reduced owing to the diode voltage drop, a level shifter is employed to recover the degraded signal into a full-scale digital signal. The schematic of the level shifter and simulated transfer curves at different temperatures and process corners are shown in fig. 4. The input transition voltage is typically $546 \mathrm{mV}$ with maximum variation of $85 \mathrm{mV}$. The transition voltage can be adjusted by changing the value of the resistor $R_{L S}$.

A two-stage comparator with a bias circuit and enable switches is designed to control the PMOS switch in the active diode. Schematic of the designed comparator is shown in fig. 5 . The bias circuit supplies a constant current to the comparator even when the supply voltage $\mathrm{V}_{\mathrm{STO}}$ changes. Thus, it guarantees that the comparator has stable performance at different supply voltages. The designed comparator has a dc gain of $99 \mathrm{~dB}$ and consumes $104 \mathrm{nA}$ from a supply voltage of $3.3 \mathrm{~V}$.

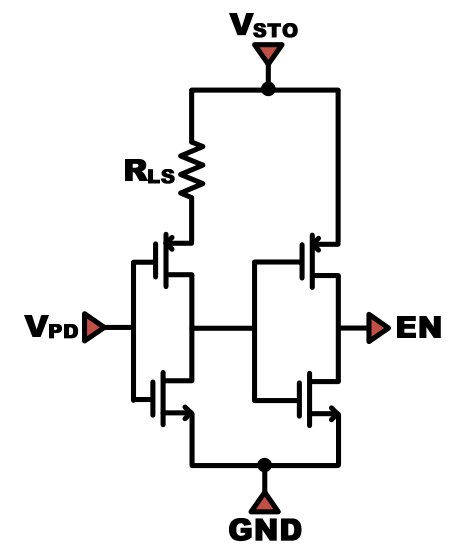

(A)

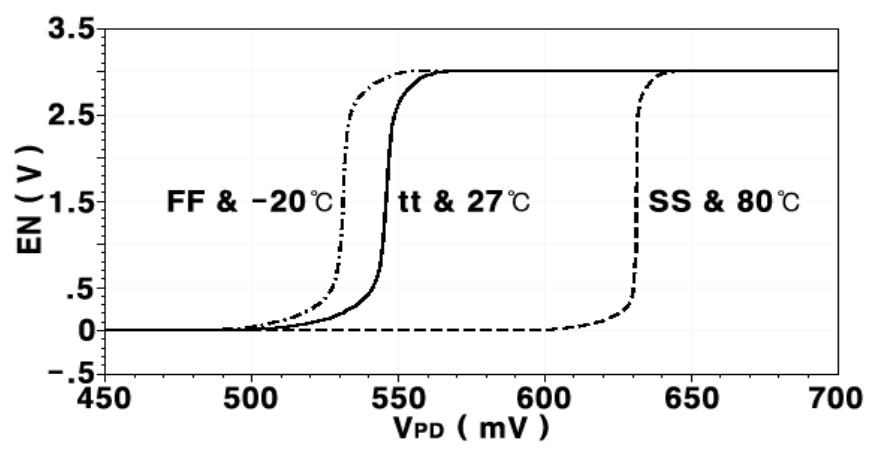

(B)

FIGURE IV. (A) SCHEMATIC OF LEVEL SHIFTER, (B) SIMULATED TRANSFER CURVES.

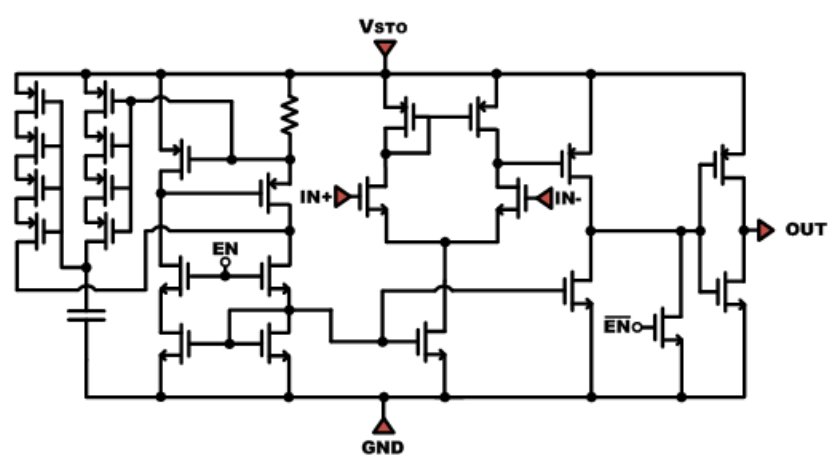

FIGURE V. SCHEMATIC OF DESIGNED COMPARATOR WITH ENABLE SWITCHES

\section{Simulation Result}

The designed FWR is simulated using a $0.35-\mu \mathrm{m}$ CMOS process. The targeted PZT generator is the Quick Pack QP20W [9] that can generate $125 \mu \mathrm{W}$ with an acceleration of $7 \mathrm{~m} / \mathrm{s}^{2}$ at $80 \mathrm{~Hz}$. This device can be simply modelled by a current source and parallel capacitor [8]. The amplitude and frequency of the sinusoidal current source are set to $3.3 \mathrm{~V}$ and 
$80 \mathrm{~Hz}$, respectively. The internal parallel capacitor is $0.2 \mu \mathrm{F}$. The selected value of the storage capacitor $\mathrm{C}_{\mathrm{STO}}$ is $47 \mu \mathrm{F}$.

Fig. 6 shows the power efficiency of the designed FWR with and without the voltage detector at different load resistance. Their efficiencies are almost same except for very small load resistances. The maximum power efficiency of the FWR without voltage detector is $99.2 \%$ at $19 \mathrm{k} \Omega$, while that with voltage detector is $99.2 \%$ at $18 \mathrm{k} \Omega$. The maximum loss by the voltage detector is $1.4 \%$ at the $5 \mathrm{k} \Omega$.

Fig. 7 shows the simulated waveforms when the vibration starts at $0 \mathrm{~s}$ and stops at $8 \mathrm{~s}$. While the vibration exists, the vibration detector functions and the output signal 'EN' follows $\mathrm{V}_{\mathrm{STO}}$, and thus, the comparators are enabled and consume 979.8nA. The FWR output maintains the peak voltage of the input signal $\mathrm{V}_{\mathrm{PZT}^{+}}$. When the vibration disappears at $8 \mathrm{~s}$, the 'EN' signal returns to $0 \mathrm{~V}$ with a small delay time $(55.3 \mathrm{~ms})$. Therefore, the comparator is disabled and the FWR consumes no power, avoiding the reduction of voltage of $\mathrm{V}_{\text {STO }}$. The FWR without the vibration detector suffers from relatively large leakage currents due to the current consumption in the comparator. The leakage current of the FWR without the vibration detector is $177.6 \mathrm{nA}$; however, the leakage current of the FWR with the vibration detector is $55 \mathrm{pA}$. It can thus be seen that using the proposed vibration detector achieves approximately 3,200 times decrease in leakage current. The performance of the proposed FWR is summarized and compared with conventional FWRs in table 1. The proposed FWR has almost zero standby leakage current and exhibits the highest maximum power efficiency.

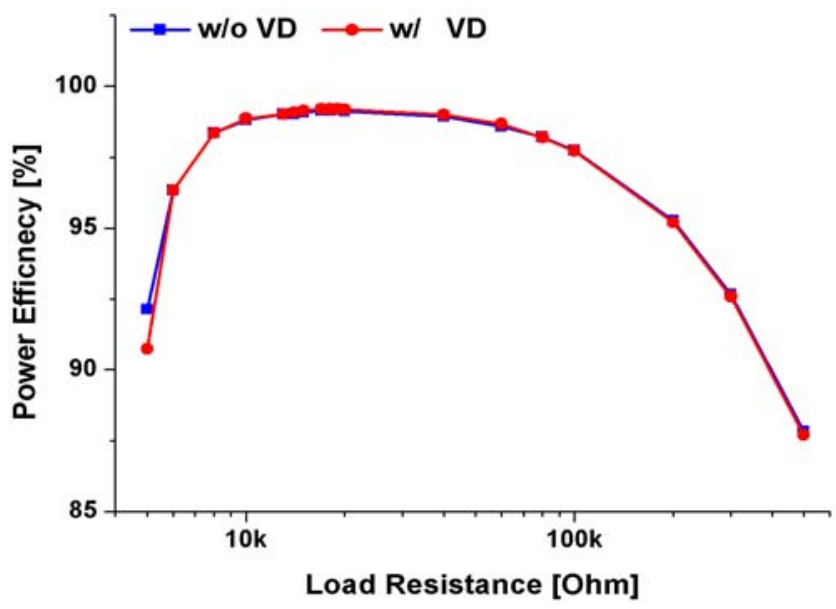

FIGURE VI. POWER EFFICIENCY OF THE FWR WITH AND WITHOUT VOLTAGE DETECTOR.

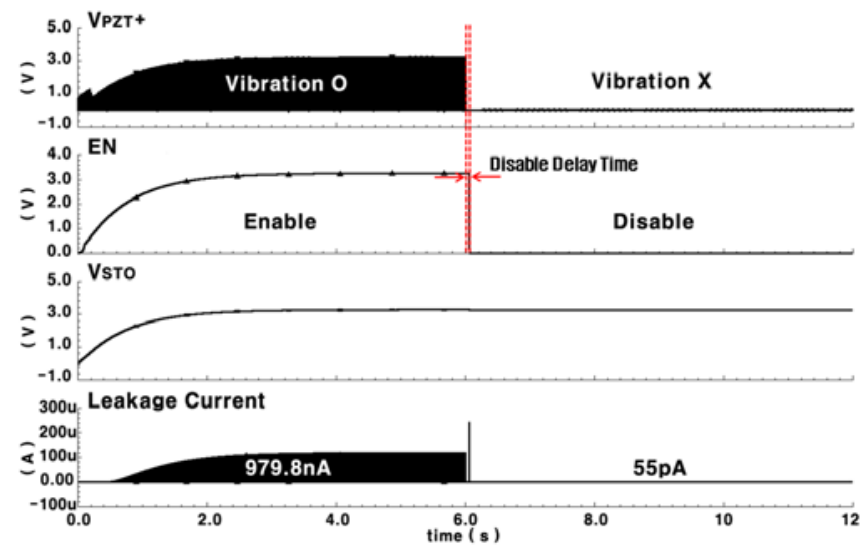

FIGURE VII. SIMULATED WAVEFORMS OF PROPOSED FWR WITH VIBRATION DETECTOR.

TABLE I. PERFORMANCE COMPARISON OF RECTIFIER FOR VIBRATION ENERGY HARVESTING.

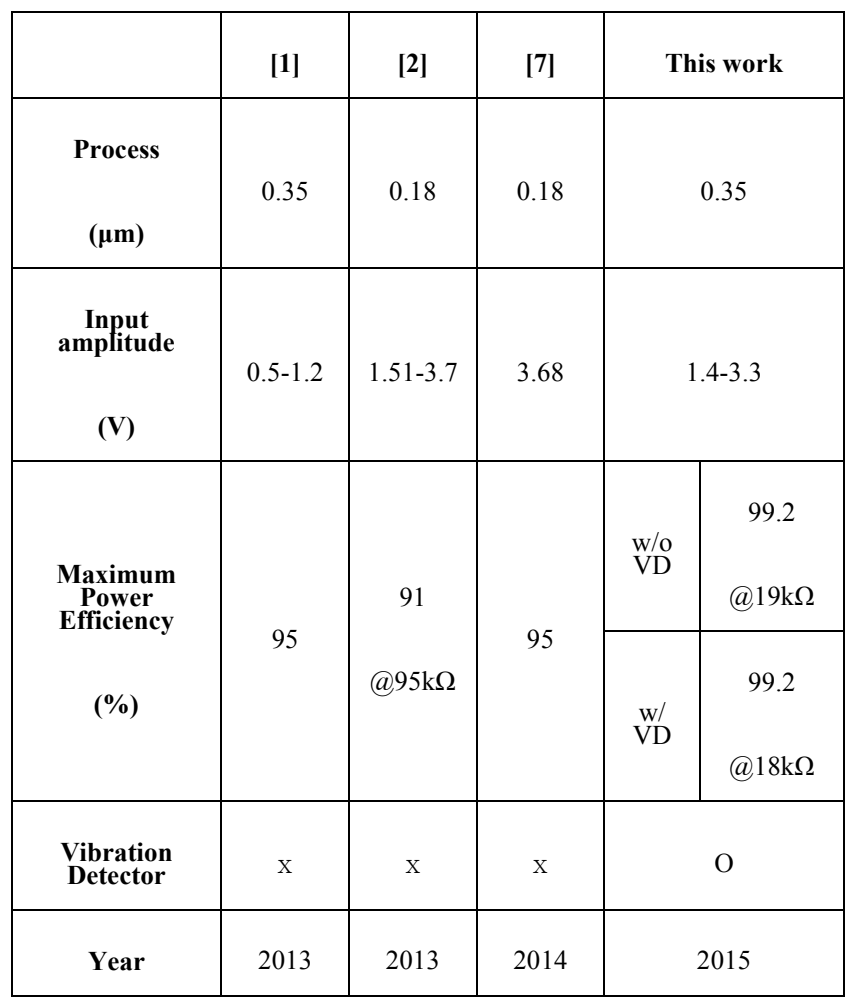

IV. CONCLUSIONS

An FWR with a simple vibration detector consisting of a peak detector and a level shifter is presented for vibrational energy harvesting applications. The FWR with the proposed vibration detector can disable the comparators in active diodes after vibration disappears, and thus, the standby leakage currents are greatly reduced compared with the case of the FWR without a vibration detector. Simulation results using a $0.35-\mu \mathrm{m}$ CMOS process show that an approximate 3,200 times decrease in standby leakage current can be achieved by using the vibration detector. The proposed scheme can be 
implemented with a little additional chip area to overcome the major problem of conventional output-powered active FWRs.

\section{ACKNOWLEDGMENT}

This research was supported by the Basic Science Research Program through the National Research Foundation of Korea (NRF) funded by the Ministry of Education, Science and Technology (2014046387) and was partially supported by IDEC.

\section{REFERENCES}

[1] Y. Sun, I. Y. Lee, C. J. Jeong, S. K. Han and S. G. Lee, "An comparator based active rectifier for vibration energy harvesting systems," 2011 13th ICACT, pp. 1404-1408, 2011.

[2] C. N. Yalung, F. R. G. Cruz, A. C. Paglinawan, J.J.R. Balbin, J. C. Dela Cruz, A. Silverio, J. A. Ngo and W. Y. Chung, "Full-wave AC-DC converter in CMOS 0.18 micron for vibration electromagnetic energy harvest,” 2014 International Conference on HNICEM, pp. 1-4, 2014.
[3] C. Sauer, et al, "Power harvesting and telemetry in CMOS for implant devices," Circuits and Systems I, IEEE Transactions on, Vol.52, No.12, pp.2605-2613, Dec., 2005.

[4] M. Ghovanloo and N. Najafi, "Fully integrated wideband high-current rectifiers for inductively powered devices," Solid-State Circuits, IEEE Journal of, Vol.39, No.11, pp.1976-1984, Nov., 2004.

[5] Y. Rao and D. P. Arnord, "An Input-Powered Vibrational Energy Harvesting Interface Circuit With Zero Standby Power," Power Electronics, IEEE Transactions on, Vol.26, No.12, pp.3524-3533, Dec., 2011.

[6] C. Peters, et al, "CMOS Integrated Highly Efficient Full Wave Rectifier," Circuits and Systems, IEEE International Symposium on, pp.2415-2418, May, 2007.

[7] A. S. Herbawi, et al, "An Ultra-Low-Power Active AC-DC CMOS Converter For Sub-1V Integrated Energy Harvesting Applications," Sensors, 2013 IEEE, pp.1-4, 2013.

[8] C. Lu, et al, "Vibration Energy Scavenging System With Maximum Power Tracking for Micropower Applications," VLSI Systems, IEEE Transactions on, Vol.19, No.11, pp.2109-2119, Nov., 2011.

[9] E. J. Yoon, I. H. Hwang, J. T. Park and C. G Yu, "Design of an Energy Harvesting Circuit Using Solar and Vibration Energy with MPPT Control," Journal of IKEEE, pp.224-234, 2012. 